\title{
The relative importance of primary food choice factors among different consumer groups: A latent profile analysis
}

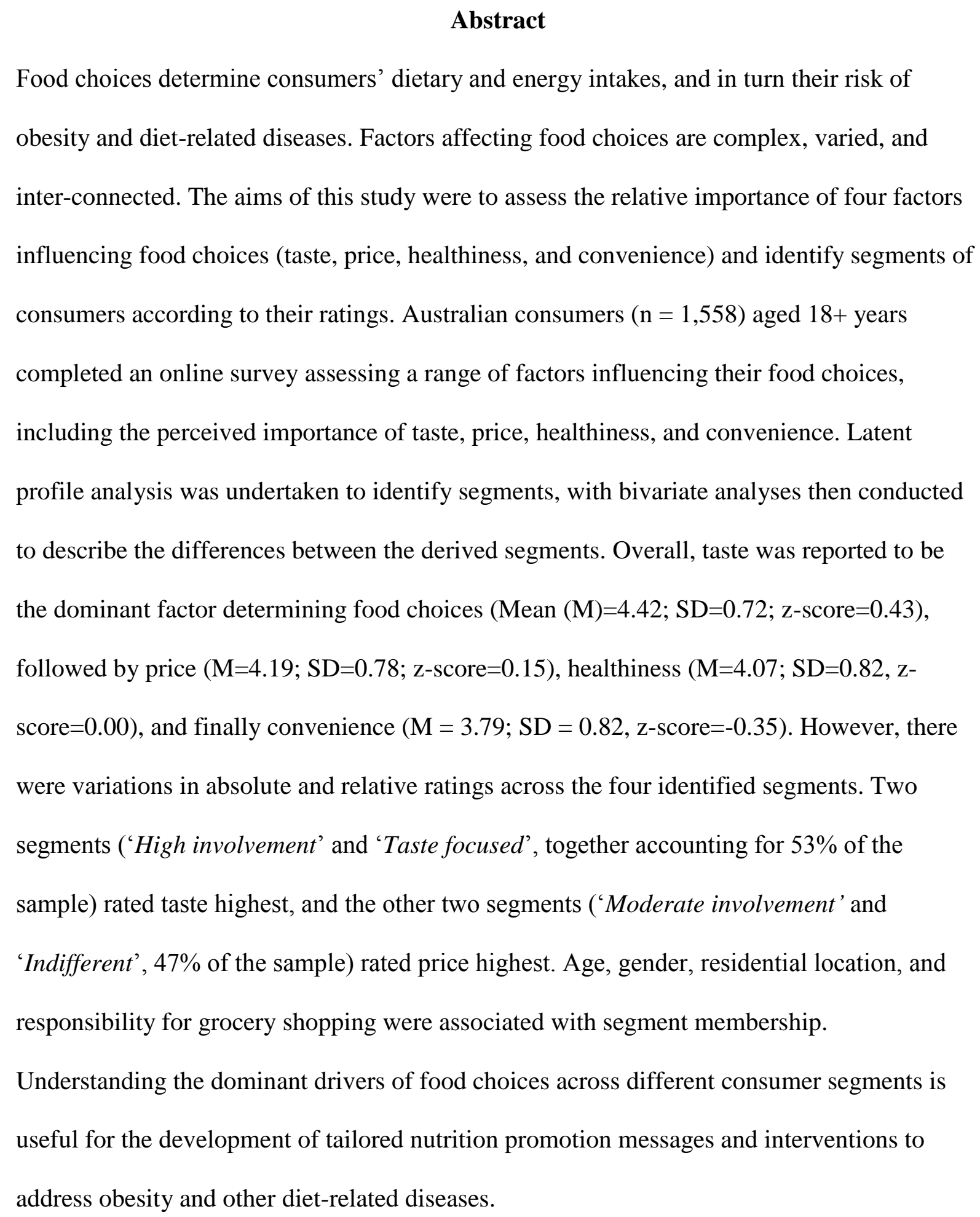

Abstract

Food choices determine consumers' dietary and energy intakes, and in turn their risk of obesity and diet-related diseases. Factors affecting food choices are complex, varied, and inter-connected. The aims of this study were to assess the relative importance of four factors influencing food choices (taste, price, healthiness, and convenience) and identify segments of consumers according to their ratings. Australian consumers $(n=1,558)$ aged $18+$ years completed an online survey assessing a range of factors influencing their food choices, including the perceived importance of taste, price, healthiness, and convenience. Latent profile analysis was undertaken to identify segments, with bivariate analyses then conducted to describe the differences between the derived segments. Overall, taste was reported to be the dominant factor determining food choices (Mean $(\mathrm{M})=4.42 ; \mathrm{SD}=0.72 ; \mathrm{z}$-score=0.43), followed by price $(\mathrm{M}=4.19 ; \mathrm{SD}=0.78$; $\mathrm{z}$-score=0.15), healthiness $(\mathrm{M}=4.07 ; \mathrm{SD}=0.82$, zscore $=0.00)$, and finally convenience $(\mathrm{M}=3.79 ; \mathrm{SD}=0.82, \mathrm{z}$-score $=-0.35)$. However, there were variations in absolute and relative ratings across the four identified segments. Two segments ('High involvement' and 'Taste focused', together accounting for 53\% of the sample) rated taste highest, and the other two segments ('Moderate involvement' and 'Indifferent', 47\% of the sample) rated price highest. Age, gender, residential location, and responsibility for grocery shopping were associated with segment membership.

Understanding the dominant drivers of food choices across different consumer segments is useful for the development of tailored nutrition promotion messages and interventions to address obesity and other diet-related diseases.

Keywords: food choice; taste; food cost; convenience; latent profile analysis 


\section{Introduction}

The Australian Dietary Guidelines recommend consuming a wide variety of foods

daily from the five main food groups (vegetables, fruit, grain cereals, lean meats and alternatives, and dairy foods and alternatives), and limiting 'discretionary' foods containing high levels of saturated fat, added salt, or sugars (National Health and Medical Research Council (NHMRC), 2013). However, few Australians meet these recommendations. Less than $10 \%$ of adults eat the recommended five serves of vegetables daily, and discretionary foods contribute more than $35 \%$ of adults' daily energy intakes (Australian Bureau of Statistics (ABS), 2016). This situation is similar around the world, and increasing numbers of people are consuming suboptimal diets that are inconsistent with dietary guidelines (Haack \& Byker, 2014; Raulio et al., 2015; Rodríguez-Rodríguez et al., 2017). Poor dietary patterns and high-energy intake contribute to obesity and a range of other nutrition-related diseases that are significant public health concerns globally (World Health Organization (WHO), 2017). Achieving a healthy diet and a healthy weight are substantial challenges. Once an individual is overweight or obese, it is very difficult to lose weight or maintain weight loss (Sumithran et al., 2011). This is confounded by a global transition in the food supply to greater availability of highly palatable, cheaper, and energy-dense foods (Crino, Sacks, Vandevijvere, Swinburn, \& Neal, 2015; Popkin, 2017; Vandevijvere, Chow, Hall, Umali, \& Swinburn, 2015). The heavy promotion of these energy-dense and nutrient-poor foods adversely influences consumers' food choice decisions (Vukmirovic, 2015). Interventions designed to counteract these forces need to be based on a detailed understanding of the factors that facilitate or hinder healthy food choices.

Among other early research on food choice motives, Steptoe, Pollard, \& Wardle (1995) developed the Food Choice Questionnaire that addresses nine factors that potentially 
51 influence food decisions: sensory appeal (encompassing appearance, taste, and smell), price,

52 healthiness of the food, convenience (easiness to prepare and availability), mood (comprising

53 mood improvement and stress reduction), natural content, weight control, familiarity, and

54 ethical concern. Of these factors, studies from different countries have consistently identified 55 taste, price, healthiness, and convenience as dominating food choices (Aggarwal, Rehm,

56 Monsivais, \& Drewnowski, 2016; Glanz, Basil, Maibach, Goldberg, \& Snyder, 1998;

57 Hebden, Chan, Louie, Rangan, \& Allman-Farinelli, 2015; Prescott, Young, O'Neill, Yau, \&

58 Stevens, 2002; Steptoe et al., 1995). While some differences have been found in how people

59 prioritise these factors, taste is typically ranked as most important, with the other factors

60 varying in their relative subsequent positions (Glanz et al., 1998; Markovina et al., 2015;

61 Onwezen et al., 2012; Prescott et al., 2002; Sautron et al., 2015; Verain, Sijtsema, \&

62 Antonides, 2016). Understanding the different consumer segments that exist in relation to the

63 prioritisation of these food choice factors is important for a wide range of public health

64 policies (Grier \& Bryant, 2005). These include policies relating to food advertising

65 regulations, food taxation, reformulation targets, and population nutrition education 66 programs.

Approaches to market segmentation vary according to the criterion variables under investigation (i.e., food choice factors in this instance), the predictor variables selected (e.g., demographic characteristics), and the analytical method used. Many segmentation studies to 70 date investigating food choice factors have focused on specific food products (e.g., Ares \& 71 Gámbaro, 2007; Bernués, Olaizola, \& Corcoran, 2003; O’Connor, Cowan, Williams, 72 O’Connell, \& Boland, 2006; Realini et al., 2014; Verain et al., 2016), and those that have 73 looked at factors affecting food choice in general have been mainly conducted in Europe 74 (e.g., Honkanen and Frewer, 2009; Kornelis, Herpen, Lans, \& Aramyan, 2010; Milošević et 75 al., 2012; Onwezen et al., 2012). In addition, there is the potential to undertake more 
comprehensive segmentation analyses by including a broader range of potential explanatory variables. Examples of such variables include health-related special dietary requirements, perceived nutrition knowledge, perceived diet healthiness, and grocery-buying role in the household (James, 2004; Moorman, Diehl, Brinberg, \& Kidwell, 2004; O’Brien et al., 2014; Shatenstein, 2008; Sobal \& Bisogni, 2009; Worsley, 2002).

In terms of analytical methods, most food choice factor segmentation studies to date have used cluster analysis (e.g., Ares \& Gámbaro, 2007; Bernués et al., 2003; Honkanen and Frewer, 2009; Milošević et al., 2012; O’Connor et al., 2006; Verain et al., 2016). In recent years, latent profile analysis has emerged as an advanced method that involves classifying individuals into different segments based on a probabilistic model-based approach that describes the distribution of the data after taking uncertainty about segment membership into account. This analysis uses statistical tests selecting the best model so that the choice of the segments is less arbitrary, thereby outperforming the traditional cluster analysis explanatory approach (Fraley \& Raftery, 1998; Hagenaars \& McCutcheon, 2009; Magidson \& Vermunt, 2002). To date, however, few studies have employed this approach in the context of food choice research (exceptions include Kornelis et al., 2010; Realini et al., 2014), and there remains the potential to use this sophisticated analysis method to obtain a deeper understanding of the interplay between different choice factors across different consumer segments.

The present study aimed to assess (a) the relative importance of the food choice factors of taste, price, convenience, and healthiness in determining consumers' food choices; (b) identify segments of consumers based on these ratings; (c) describe the characteristics of derived segments; and (d) consider the results for the food policy and program implications. This study extends prior food choice segmentation research by investigating across food types, applying a wide range of predictor variables, and using latent profile analysis to 
101

identify discrete consumer segments. The results are interpreted in terms of the implications for nutrition policies and programs.

\section{Materials and methods}

This study was part of a larger research project assessing the influence of nutrition information and food labelling on Australians' food choices (Authors, 2017). Ethics approval for the project was obtained from the Curtin University Human Research Ethics Committee (approval number: RDHS-11-15) and all participants provided informed consent.

\subsection{Sample}

In total, 1,558 adults completed an online survey via PureProfile, a web panel provider with ISO accreditation (Standards 20250 and 26362). Gender, age, and SES quotas were set to ensure gender and age population representativeness and an over-sampling of lower SES respondents (see Table 1). The intentional over-representation of lower SES respondents reflects their greater risk of nutrition-related problems, including obesity

(Australian Institute of Health \& Welfare (AIHW), 2016; Bonaccio et al., 2012).

Insert Table 1 here

\subsection{Measures}

Captured socio-demographic information included gender, age, education (1-

$<$ Tertiary education; 2- $\geq$ Tertiary education), annual gross household income (1 - Less than $\$ 30,000$ to 8 - $\$ 250,000$ or more), parent status, and residential postcode (used to determine SES according to the Australian Bureau of Statistics' Socio-Economic Indexes for Areas 
126 (SEIFA) classification (ABS, 2018) and metropolitan or regional location, as per the

Australian Statistical Geography Standard (ABS, 2013)). For each of the food choice factors of taste, price, convenience, and healthiness, respondents were asked "How important are these things to you when choosing food to eat or buy for yourself?", with responses recorded on five-point scales ranging from 1 - Very unimportant to 5 - Very important.

A range of potential predictor variables was included in the present study based on those proposed or demonstrated to be related to food choice decisions in previous research (Moorman et al., 2004; O’Brien et al., 2014; Sobal \& Bisogni, 2009; Steenhuis, Waterlander, \& de Mul, 2011; Wardle et al., 2004). Respondents reported whether they were the main grocery buyer for the household (1-Yes, 2 - No, and 3-Share job equally; responses were dichotomised in to 1 - Yes and 2 - No or share responsibilities). Respondents also reported whether they had any special dietary requirements relating to diabetes, heart disease, high cholesterol, and/or high blood pressure. Responses for each health condition were combined to create a special dietary requirement variable (1 - Had no special dietary requirements and 2 - Had a special dietary requirement). Self-rated nutrition knowledge was assessed with the item "Compared to most people, I know quite a lot about nutrition", with response options ranging from 1 - Strongly disagree to 5 - Strongly agree. Respondents rated the perceived healthiness of their diet on a four-point scale: 1 - I eat a very healthy diet to 4 - I eat a very unhealthy diet (reverse coded for analysis purposes). Body Mass Index (BMI) was calculated from respondents' self-reported weight and height.

\subsection{Data analyses}

Latent profile analysis was conducted using the rated importance of the food choice factors of taste, price, health, and convenience as continuous variables (Hagenaars \& McCutcheon, 2009). Z-scores for each of the rated food choice factors of taste, price, 
healthiness, and convenience were calculated to standardise the data within each consumer $(\mathrm{M}=0$ and $\mathrm{SD}=1)$, and then used to compute models characterised by two- to six-profile segments. The robust maximum likelihood estimation was used for each of the computed models, with 300 iterations and a constraints value of 15 to restrict the class-specific residual variances equal across the latent classes to attain model parsimony (Muthén \& Asparouhov, 2009). The 300 best solutions were then retained for final stage optimisation (Hipp \& Bauer, 2006). The selection of the optimal model was made by considering statistical criteria and whether additional segments provided any further information, with the aim being the attainment of solution parsimony (Swait, 1994). The fit statistics of Akaike Information Criteria (AIC), Bayesian Information Criteria (BIC), Sample-size Adjusted BIC (SABIC), and entropy values were examined to determine the optimal model. Exhibiting the lowest AIC, BIC, and SABIC and a higher entropy value are indicative of the optimal solution (DiStefano \& Kamphaus, 2006; Fraley \& Raftery, 1998; Nylund, Asparouhov, \& Muthén, 2007). Further considerations were the ease of interpretation of the solution and the derivation of a model that did not include a segment comprising less than $5 \%$ of the sample (Marsh, Lüdtke, Trautwein, \& Morin, 2009; Nylund et al., 2007). One-way ANOVAs were then computed to test for significant differences in the z-scores of the food choice factors between the derived segments, and mean-comparison tests were used to test for significant differences within segments on the z-scores of the food choice factors. Each respondent was allocated to a latent profile based on the highest posterior probabilities approach. To test for significant differences between the derived segments, bivariate analyses were conducted, either one-way ANOVAs (with Bonferroni post-hoc tests for continuous predictor variables) or chi-square tests for categorical predictor variables (with multiple chi-square comparison tests used when significant outcomes emerged for predictor variables with more than two categories). All analyses were conducted using Stata version 15.1 software (StataCorp, 2017). 


\section{Results}

\subsection{Descriptive statistics}

Across the entire sample, taste was rated as the most important determinant of food choice, with a mean score of 4.42 on the 5-point scale $(\mathrm{SD}=0.72, \mathrm{z}$-score $=0.43)$. This was followed by price $(M=4.19, S D=0.78, z$-score $=0.15)$ and healthiness $(M=4.07, S D=$ $0.82, \mathrm{z}$-score $=0.00)$. Convenience was rated lowest $(\mathrm{M}=3.79, \mathrm{SD}=0.82, \mathrm{z}$-score $=-0.35)$ The z-score differences between the four food choice determinants were significant $(p<0.001$ for each paired comparison).

\subsection{Fit statistics}

The computed 2-to 6-segment models were converged on well-replicated solutions.

The AIC, BIC, and SABIC values continually decreased as the number of segments increased. The 4-segment model was selected as the most appropriate profile solution based on: (i) relatively low AIC, BIC, and SABIC values than the preceding models; (ii) the fourth segment provided a different mean pattern of the food choice factors than the segments identified in the 3-segment model, thereby providing new information; (iii) the 5- and 6segment models did not provide distinct latent profiles compared to the 4-segment model (Marsh et al., 2009); (iv) the 5- and 6-segment models included at least one segment comprising less than $5 \%$ of the sample; and (v) ease of interpretation and parsimony of the solution. In terms of entropy values, the 2- through 6-segment models resulted in similar outcomes. The entropy value of 0.997 for the 4 -segment model indicates that $99.7 \%$ of the sample was classified appropriately, which is far higher than the 'high' threshold of $\geq 0.80$ 
201

(Clark \& Muthen, 2009; Kamata, Kara, Patarapichayatham, \& Lan, 2018). The average posterior probabilities of the 4 -segment model ranged from 0.79 to $1.00($ Segment $1:$ mean $=$ $0.88,95 \%$ CI $[0.87,0.89] ;$ Segment 2: mean $=1.00,95 \%$ CI $[1.00,1.00]$; Segment 3: mean $=$ $0.79,95 \%$ CI $[0.77,0.82]$; Segment 4 : mean $=0.99,95 \%$ CI $[0.98,1.00])$, demonstrating a high classification level and well-separated profiles (>0.70 rule-of-thumb: Nagin, 2005).

\section{Insert Table 2 here}

\subsection{Four-segment latent profile solution}

The means and corresponding $\mathrm{z}$-scores for the food choice factors across the four segments are shown in Table 2 and the distribution patterns of the derived latent profile segments are depicted in Figure 1. Each of the four segments was narrowly spread over the latent space. However, the classes were well separated from each other and classified appropriately as the average posterior probabilities and entropy values indicate. Segments 1 and 3 prioritised taste while Segments 2 and 4 prioritised price. Segments 1 and 2 comprised the largest number of respondents, together accounting for $83 \%$ of the total sample. These two segments had relatively high scores for all variables, indicating that these four factors are key food choice criteria for the large majority of Australian consumers. Z-scores for all factors were especially high for Segment 1 relative to the other segments, with the partial exception of taste for which both Segment 1 and Segment 3 had the highest mean and the highest z-score. In accordance with the high scores across all four food choice factors, Segment 1 was given the title High involvement. This terminology derives from the consumer research literature where involvement refers to a consumer's level of interest in a particular product (Mittal and Lee, 1989). 
Members of Segment 2 demonstrated the second highest scores for each factor, with

relatively little variability across the four factors. This segment was titled Moderate

involvement to align with the moderate $\mathrm{z}$-scores and means of around 4 on the 5-point scales.

Segment 3 was characterised by a substantially higher score for taste relative to the three

other factors, illustrating the particular importance of this choice criterion for members of this group. This segment was accordingly titled Taste focused. Segment 4 comprised respondents with the lowest scores for all four food choice factors, and was the only segment for which taste ranked last. Based on this profile, Segment 4 was titled Indifferent.

Insert Table 2 here

\subsection{Characteristics of segment members}

Table 3 describes the identified segments according to the predictor variables applied in the analyses. The two segments of High involvement and Indifferent featured the most distinguishing characteristics. The High involvement segment was the only one dominated by women, and it had a significantly larger proportion of those who described themselves as the primary grocery shoppers in their households. Those allocated to this group were least likely to live in the metropolitan area and were older on average compared to members of the

Moderate involvement and Indifferent segments. By comparison, most members of the Indifferent segment were male and on average they were the youngest in the sample, the most 247 likely to live in metropolitan areas, and the least likely to do the household food shopping. 248 There were no unique characteristics attributed to those in the Moderate involvement and 249 Taste focused segments. 
Insert Table 3 here

\section{Discussion}

This study aimed to assess consumers' relative ratings of the primary factors

determining their food choices and identify segments according to these ratings. Among the four identified segments, taste was rated highest for two of the segments and also received an average rating of 4 or more on a 5-point scale for three segments that together comprised $93 \%$ of the sample.

This finding relating to the importance of taste in driving food choices is consistent with previous studies (Aggarwal et al., 2016; Glanz et al., 1998; Hebden et al., 2015; Honkanen and Frewer, 2009; Onwezen et al., 2012; Prescott et al., 2002; Sautron et al., 2015; Steptoe et al., 1995; Verain et al., 2016), and illustrates that taste perceptions should play a central role in interventions designed to improve people's diets.

Of the four segments identified in the present study, the High involvement and Taste focused segments provided the highest possible ratings for taste (average rating of 5 on a 5point scale; z-score $=1.13$ ), while the Moderate involvement and Indifferent segments prioritised price. By comparison, members of the Indifferent segment were more likely to live in metropolitan areas and to be younger, the latter being consistent with previous studies finding younger people to be less interested in food generally (Ares \& Gámbaro, 2007; Carrillo et al., 2011). The Taste focused segment tended to be comprised of older respondents relative to respondents assigned to groups that prioritised other choice factors or were

Indifferent. While dietary guidelines for chronic disease prevention urge consumers to prioritise health when making dietary decisions, this choice factor ranked third for a large majority of the sample, including those with special dietary requirements, higher perceived 
healthiness of usual diet, and higher self-rated nutrition knowledge. These outcomes highlight the importance of ensuring that healthy foods are presented as tasty and affordable to increase their overall attractiveness (Pettigrew, 2016).

The relatively low rating of convenience in the present study was unexpected given previous research indicating that this factor is often ranked second after taste (Hebden et al., 2015; Honkanen and Frewer, 2009; Milosevic et al., 2012; Onwezen et al., 2012; Prescott et al., 2002). This variation in results may be at least partially attributable to the different cultural contexts (Honkanen and Frewer, 2009; Milosevic et al., 2012; Onwezen et al., 2012) and age groups under study (Hebden et al., 2015). A further reason may be the 'hygiene factor' phenomenon that occurs when specific factors are not considered to be as critical as others because although they are important, they are not frequently encountered as problems (Lee, Chen, \& Huang, 2018). The extensive availability of packaged foods in many countries may make convenience an assumed attribute and hence one that is less salient in purchase decisions compared to factors with greater variability.

Of note is that health-related variables such as BMI, self-rated nutrition knowledge, being on a special diet, and perceived healthiness of usual diet were not significant predictors of segment allocation. In the case of BMI, the results are consistent with previous work indicating that weight status is not significantly associated with taste and price preferences (Cox et al., 1998; Hebden et al., 2015; Honkanen \& Frewer, 2009; Salbe, DelParigi, Pratley, Drewnowski, \& Tataranni, 2004). The lack of prior research including special dietary requirements, nutrition knowledge, and perceived diet healthiness as food choice predictors precludes comparisons to previous literature on the basis of these variables. However, the non-significant results relating to being on a special diet were unexpected given that respondents with these specific conditions might have been expected to congregate into segments that rated health more highly. 


\subsection{Policy and practice implications}

Given evidence that food promotion plays an important role in consumers'

expectations of food acceptability (Elder \& Krishna, 2010; Krishna, Cian, \& Sokolova, 2016), the results of the present study highlight the importance of promoting the tastiness of healthy foods and demonstrating ways to make healthy foods more pleasurable to help shift entrenched beliefs about healthy foods being less enjoyable (Freeland-Graves \& Nitzke, 2013; Mela, 2006; Raghunathan, Naylor, \& Hoyer, 2006). Interventions focusing on the palatability of healthy foods have reported improvements in diet quality without encouraging overconsumption (Leahy, Birch, \& Rolls, 2008; Poortvliet et al., 2007). However, such efforts need to be accompanied by broader food advertising regulations to limit the highly prevalent unhealthy food marketing that tends to focus on taste (Galbraith- Emami \& Lobstein, 2013).

The second ranking of price in this study has implications for food pricing policies and interventions. Healthy foods are often perceived as expensive (Carrete \& Arroyo, 2014; Pettigrew \& Pescud, 2013), yet healthier diet baskets for the average family household have been found to be less costly than unhealthy food baskets (Lee, Kane, Ramsey, Good, \& Dick, 2016). Public health groups and governments could engage in efforts to correct misperceptions about the cost of healthy foods, including through the use of consumer education programs that have been demonstrated to be effective in this regard (Pettigrew, Moore, Pratt, \& Jongenelis, 2016; Pettigrew, Jongenelis, Biagioni, Pratt, \& Moore, 2018).

Other potentially useful strategies include increasing the cost of unhealthy foods using policies such as taxation and providing subsidies for healthy foods such as fruit and vegetables (Andreyeva, Long, \& Brownell, 2010; Block, Chandra, McManus, \& Willett, 2010; Brownell et al., 2010). Interventions that lower the price of healthy foods (Ball et al., 
2015; Horgen \& Brownell, 2002; Ni Mhurchu, Blakely, Jiang, Eyles, \& Rodgers, 2010) and increase the price of unhealthy foods (Block et al., 2010; Ni Mhurchu et al., 2010; Colchero, Guerrero-López, Molina, \& Rivera, 2016) have been demonstrated to produce modest improvements in diet quality.

\subsection{Study limitations and strengths}

A primary limitation of this study was its cross-sectional design, which prevents determination of the extent to which predictor variables may be merely associated with the food choice factors. In addition, the four food choice factors (taste, price, healthiness, and convenience) were assessed using broad survey items that captured a general snapshot of consumers' relative prioritisation of these factors. It is likely that ratings would vary depending on the foods and purchasing situations under consideration. For example, taste may drive a decision to choose chocolate, healthiness may drive a decision to choose vegetables, and convenience is a likely a dominant factor when selecting takeaway foods. Specific products are also likely to engender a broader range of key food choice factors (e.g., perishability in the case of fruit and vegetables (Chapman et al., 2016) and ethical motives for coffee (Davies and Gutsche, 2016)).

A further limitation was the lack of inclusion of food intake data or other forms of behavioural data. Future studies could build on the present results by incorporating food frequency questionnaires to assess the relationship between stated food choice factors and actual dietary patterns. Alternatively, a combination of in-home observations and interviews could be useful for contextualising the roles of competing food choice determinants.

Similarly, questionnaires could include involvement scales (e.g., Marshall \& Bell, 2004) that would enable the formal measurement of the involvement construct to determine the extent to which this variable impacts on choice criteria. Finally, the survey questions focused on 
factors that influenced individual food choice decisions, and different results may have been obtained if participants with families were asked about their food choice decisions for the entire household. Future research could investigate how food choice factors vary in importance for different food categories versus overall eating patterns and for individuals versus households.

Relatively few differences in consumer attributes between the different segments emerged, indicating that other factors that were not included in this study may be having a substantial influence on the outcomes. These could potentially include a wide range of social, cultural, and environmental factors that are recognised to be important determinants of eating patterns (Cruwys, Bevelander, \& Hermans, 2015; Menezes, Diez Roux, Costa, \& Lopes, 2018). Future research may attempt to incorporate a more diverse range of predictor variables to provide greater insights into the factors that demarcate particular groups of consumers.

362 Strengths of the present study were the large sample, the intentional over-representation of 363 people from socioeconomically disadvantaged backgrounds, and the use of latent profile 364 analysis methods.

\section{Conclusion}

This study contributes to the growing evidence that taste and price are the most important factors determining consumers' food choice decisions. Although consideration of food healthiness in consumption decisions is important for preventing nutrition-related chronic health conditions, the findings of the present study show that this factor was rated lower relative to taste and price for the large majority of respondents, regardless of levels of 373 perceived diet healthiness, perceived nutrition knowledge, and having special dietary 374 requirements. This suggests that in order to assist in preventing and controlling obesity and 
diet-related diseases, health promotion interventions may need to incorporate messages about healthy foods being tasty and enjoyable and policy interventions should ensure healthy foods are affordable. Traditional nutrition programs and messages that reinforce the importance of healthiness when choosing foods may not be as successful as messaging on taste and price considerations.

\section{References}

Aggarwal, A., Rehm, C. D., Monsivais, P., \& Drewnowski, A. (2016). Importance of taste, nutrition, cost and convenience in relation to diet quality: Evidence of nutrition resilience among US adults using National Health and Nutrition Examination Survey (NHANES) 2007-2010. Preventive Medicine, 90, 184-192. https://doi.org/10.1016/j.ypmed.2016.06.030.

Ares, G., \& Gámbaro, A. (2007). Influence of gender, age and motives underlying food choice on perceived healthiness and willingness to try functional foods. Appetite, 49, 148-158. https://doi.org/10.1016/j.appet.2007.01.006.

Andreyeva, T., Long, M. W., \& Brownell, K. D. (2010). The impact of food prices on consumption: A systematic review of research on the price elasticity of demand for food. American Journal of Public Health, 100(2), 216-222. https://doi.org/10.2105/ajph.2008.151415.

Australian Bureau of Statistics. (2013). 1270.0.55.005 - Australian Statistical Geography Standard (ASGS): Volume 5 - remoteness structure, July 2011. http://www.abs.gov.au/ausstats/abs@.nsf/mf/1270.0.55.005?OpenDocument/ Accessed 1 February 2019.

Australian Bureau of Statistics. (2016). 4364.0.55.012 - Australian Health Survey: Consumption of food groups from the Australian dietary guidelines, 2011-2012. 


\section{Canberra.}

http://www.abs.gov.au/ausstats/abs@.nsf/Lookup/4364.0.55.012main+features1201112/ Accessed 1 February 2019.

Australian Bureau of Statistics. (2017). 31010DO002_201612 - Australian Demographic Statistics, Dec 2016: Age distribution, by sex, preliminary-30 June 2016, data cubes. Canberra: ABS. http://www.abs.gov.au/AUSSTATS/abs@.nsf/DetailsPage/3101.0Dec\%202017?Open Document/ Accessed 2 February 2019.

Australian Bureau of Statistics. (2018). 2033.0.55.001 - Census of Population and Housing: Socio-Economic Indexes for Areas (SEIFA), Australia, 2016. Canberra: ABS. http://www.abs.gov.au/ausstats/abs@.nsf/mf/2033.0.55.001/ Accessed 2 February 2019.

Australian Institute of Health \& Welfare. (2016). Australia's Health 2016, Chapter 5. Canberra, Australia. https://www.aihw.gov.au/reports/australias-health/australiashealth-2016/contents/population-groups / Accessed 10 February 2019.

Ball, K., McNaughton, S. A., Le, H. N., Gold, L., Ni Mhurchu, C., Abbott, G., . . Crawford, D. (2015). Influence of price discounts and skill-building strategies on purchase and consumption of healthy food and beverages: outcomes of the Supermarket Healthy Eating for Life randomized controlled trial. The American Journal of Clinical Nutrition, 101(5), 1055-1064. https://doi.org/10.3945/ajen.114.096735.

Bernués, A., Olaizola, A., \& Corcoran, K. (2003). Extrinsic attributes of red meat as indicators of quality in Europe: An application for market segmentation. Food Quality and Preference, 14(4), 265-276. https://doi.org/10.1016/S0950-3293(02)00085-X.

Block, J. P., Chandra, A., McManus, K. D., \& Willett, W. C. (2010). Point-of-purchase price and education intervention to reduce consumption of sugary soft drinks. American 
Journal of Public Health, 100(8), 1427-1433.

https://doi.org/10.2105/ajph.2009.175687.

Bonaccio, M., Bonanni, A. E., Di Castelnuovo, A., De Lucia, F., Donati, M. B., de Gaetano, G., \& Iacoviello, L. (2012). Low income is associated with poor adherence to a Mediterranean diet and a higher prevalence of obesity: Cross-sectional results from the Moli-sani study. BMJ Open, 2(6). https://doi.org/10.1136/bmjopen-2012-001685.

431 Brownell, Farley, T., Willett, W., Popkin, B. M., Chaloupka, F., Thompson, J. W., \&

432 Ludwig, D. (2010). The public health and economic benefits of taxing sugarsweetened beverages. The New England Journal of Medicine, 362(13), 1250-1250. https://doi.org/10.1056/NEJMx100008.

Carrete, L., \& Arroyo, P. (2014). Social marketing to improve healthy dietary decisions: Insights from a qualitative study in Mexico. Qualitative Market Research, 17(3), 239263. https://doi.org/10.1108/QMR-11-2011-0023.

Carrillo, E., Varela, P., Salvador, A., \& Fiszman, S. (2011). Main factors underlying consumers' food choice: A first step for the understanding of attitudes toward "healthy eating”. Journal of Sensory Studies, 26(2), 85-95. https://doi.org/10.1111/j.1745459X.2010.00325.x.

Chapman, K., Havill, M., Watson, W. L., Wellard, L., Hughes, C., Bauman, A., \& AllmanFarinelli, M. (2016). Time to address continued poor vegetable intake in Australia for prevention of chronic disease. Appetite, 107, 295-302. https://doi.org/10.1016/j.appet.2016.08.003.

Clark, S. L., \& Muthen, B. (2009). Relating latent class analysis results to variables not included in the analysis. Los Angeles: University of California. http://www.statmodel.com/download/relatinglca.pdf/ Accessed 11 February 2019. 
Colchero, M. A., Guerrero-López, C. M., Molina, M., \& Rivera, J. A. (2016). Beverages Sales in Mexico before and after Implementation of a Sugar Sweetened Beverage Tax. PLoS ONE, 11(9), e0163463. https://doi.org/10.1371/journal.pone.0163463.

Cox, D. N., van Galen, M., Hedderley, D., Perry, L., Moore, P. B., \& Mela, D. J. (1998). Sensory and hedonic judgments of common foods by lean consumers and consumers with obesity. Obesity Research, 6(6), 438. https://doi.org/10.1002/j.15508528.1998.tb00376.x.

Crino, M., Sacks, G., Vandevijvere, S., Swinburn, B., \& Neal, B. (2015). The influence on population weight gain and obesity of the macronutrient composition and energy density of the food supply. Current Obesity Reports, 4(1), 1-10. https://doi.org/10.1007/s13679-014-0134-7.

Cruwys, T., Bevelander, K. E., \& Hermans, R. C. J. (2015). Social modeling of eating: A review of when and why social influence affects food intake and choice. Appetite, 86, 3-18. https://doi.org/10.1016/j.appet.2014.08.035.

Davies, I. A., \& Gutsche, S. (2016). Consumer motivations for mainstream "ethical" consumption. European Journal of Marketing, 50(7/8), 1326-1347. https://doi.org/10.1108/EJM-11-2015-0795.

DiStefano, C., \& Kamphaus, R. W. (2006). Investigating subtypes of child development: A comparison of cluster analysis and latent class cluster analysis in typology creation. Educational and Psychological Measurement, 66(5), 778-794. https://doi.org/10.1177/0013164405284033.

Elder, R. S., \& Krishna, A. (2010). The effects of advertising copy on sensory thoughts and perceived taste. Journal of Consumer Research, 36(5), 748-756. https://doi.org/10.1086/605327. 
473 Fraley, C., \& Raftery, A. E. (1998). How many clusters? Which clustering method? Answers via model-based cluster analysis. The computer Journal, 41(8), 578-588.

Freeland-Graves, J. H., \& Nitzke, S. (2013). Position of the academy of nutrition and dietetics: Total diet approach to healthy eating. Journal of the Academy of Nutrition and Dietetics, 113(2), 307-317. https://doi.org/10.1016/j.jand.2012.12.013.

Galbraith- Emami, S., \& Lobstein, T. (2013). The impact of initiatives to limit the advertising of food and beverage products to children: A systematic review. Obesity Reviews, 14(12), 960-974. https://doi.org/10.1111/obr.12060.

Glanz, K., Basil, M., Maibach, E., Goldberg, J., \& Snyder, D. A. N. (1998). Why Americans eat what they do. Journal of the Academy of Nutrition and Dietetics, 98(10), 11181126. https://doi.org/10.1016/S0002-8223(98)00260-0.

Grier, S., \& Bryant, C. A. (2005). Social marketing in public health. Annual Review of Public Health, 26, 319-339. https://doi.org/10.1146/annurev.publhealth.26.021304.144610.

Haack, S. A., \& Byker, C. J. (2014). Recent population adherence to and knowledge of United States federal nutrition guides, 1992-2013: A systematic review. Nutrition Reviews, 72(10), 613-626. https://doi.org/10.1111/nure.12140.

Hagenaars, J. A. P., \& McCutcheon, A. L. (2009). Applied latent class analysis. Cambridge University Press, (Chapter 3).

Hebden, L., Chan, H. N., Louie, J. C., Rangan, A., \& Allman- Farinelli, M. (2015). You are what you choose to eat: Factors influencing young adults' food selection behaviour. Journal of Human Nutrition and Dietetics, 28(4), 401-408. https://doi.org/10.1111/jhn.12312.

Hipp, J. R., \& Bauer, D. J. (2006). Local solutions in the estimation of growth mixture models. Psychological Methods, 11(1), 36-53. https://doi.org/10.1037/1082989X.11.1.36 
Honkanen, P., \& Frewer, L. (2009). Russian consumers' motives for food choice. Appetite, 52(2), 363-371. https://doi.org/10.1016/j.appet.2008.11.009.

Horgen, K. B., \& Brownell, K. D. (2002). Comparison of price change and health message interventions in promoting healthy food choices. Health Psychology, 21(5), 505-512. https://doi.org/10.1037/0278-6133.21.5.505.

James, D. (2004). Factors influencing food choices, dietary intake, and nutrition-related attitudes among African Americans: Application of a culturally sensitive model. Ethnicity and Health, 9(4), 349-367. https://doi.org/10.1080/1355785042000285375.

Kamata, A., Kara, Y., Patarapichayatham, C., \& Lan, P. (2018). Evaluation of Analysis Approaches for Latent Class Analysis with Auxiliary Linear Growth Model. Frontiers in Psychology, 9, 130. https://doi.org/10.3389/fpsyg.2018.00130.

Kornelis, M., Herpen, E. v., Lans, I. v. d., \& Aramyan, L. (2010). Using non-food information to identify food-choice segment membership. Food Quality and Preference, 21(5), 512-520. https://doi.org/10.1016/j.foodqual.2010.01.007.

Krishna, A., Cian, L., \& Sokolova, T. (2016). The power of sensory marketing in advertising. Current Opinion in Psychology, 10, 142-147. https://doi.org/10.1016/j.copsyc.2016.01.007.

Leahy, K. E., Birch, L. L., \& Rolls, B. J. (2008). Reducing the energy density of an entree decreases children's energy intake at lunch. Journal of the American Dietetic Association, 108(1), 41-48. https://doi.org/10.1016/j.jada.2007.10.015.

Lee, A. J., Kane, S., Ramsey, R., Good, E., \& Dick, M. (2016). Testing the price and affordability of healthy and current (unhealthy) diets and the potential impacts of policy change in Australia. BMC Public Health, 16(1), 315. https://doi.org/10.1186/s12889-016-2996-y. 
Lee, W.-I., Chen, C.-C., \& Huang, Y.-H. (2018). The moderating effect on purchasing intention in the health food industry. International Journal of Management, Economics and Social Sciences, 7(2), 155-174.

Magidson, J., \& Vermunt, J. (2002). Latent class models for clustering: A comparison with K-means. Canadian Journal of Marketing Research, 20(1), 36-43.

Markovina, J., Stewart-Knox, B. J., Rankin, A., Gibney, M., de Almeida, M. D. V., Fischer, A., .. . Frewer, L. J. (2015). Food4Me study: Validity and reliability of Food Choice Questionnaire in 9 European countries. Food Quality and Preference, 45, 26-32. https://doi.org/10.1016/j.foodqual.2015.05.002.

Marshall, D., \& Bell, R. (2004). Relating the food involvement scale to demographic variables, food choice and other constructs. Food Quality and Preference, 15(7-8), 871-879.

Marsh, H. W., Lüdtke, O., Trautwein, U., \& Morin, A. J. S. (2009). Classical latent profile analysis of academic self-concept dimensions: Synergy of person- and variablecentered approaches to theoretical models of self-concept. Structural Equation Modeling: A Multidisciplinary Journal, 16(2), 191-225. https://doi.org/10.1080/10705510902751010.

Mela, D.J. (2006). Eating for pleasure or just wanting to eat? Reconsidering sensory hedonic responses as a driver of obesity. Appetite, 47(1), 10-17. https://doi.org/10.1016/j.appet.2006.02.006.

Menezes, M. C. d., Diez Roux, A. V., Costa, B. V. d. L., \& Lopes, A. C. S. (2018). Individual and food environmental factors: Association with diet. Public Health Nutrition, 21(15), 2782-2792. https://doi.org/10.1017/S1368980018001623. 
545 Milošević, J., Žeželj, I., Gorton, M., \& Barjolle, D. (2012). Understanding the motives for 546 food choice in Western Balkan Countries. Appetite, 58(1).

$547 \quad$ https://doi.org/10.1016/j.appet.2011.09.012.

548 Mittal, B., \& Lee, M.-S. (1989). A causal model of consumer involvement. Journal of $549 \quad$ Economic Psychology, 10(3), 363-389.

550 Moorman, C., Diehl, K., Brinberg, D., \& Kidwell, B. (2004). Subjective knowledge, search 551 locations, and consumer choice. Journal of Consumer Research, 31(3), 673-680.

552 Muthén, B.O., \& Asparouhov, T. (2009). Multilevel regression mixture analysis. Journal of

554 National Health and Medical Research Council. (2013). Australian Dietary Guidelines.

555 Canberra, Australia. https://nhmrc.gov.au/about-us/publications/australian-dietary$556 \quad$ guidelines/ Accessed 9 February 2019.

557 Ni Mhurchu, C., Blakely, T., Jiang, Y., Eyles, H. C., \& Rodgers, A. (2010). Effects of price 558 discounts and tailored nutrition education on supermarket purchases: A randomized controlled trial. The American Journal of Clinical Nutrition, 91(3), 736-747. https://doi.org/10.3945/ajen.2009.28742.

Nylund, K. L., Asparouhov, T., \& Muthén, B. O. (2007). Deciding on the number of classes in latent class analysis and growth mixture modeling: A Monte Carlo Simulation study. Structural Equation Modeling: A Multidisciplinary Journal, 14(4), 535-569. https://doi.org/10.1080/10705510701575396.

O’Brien, M. C., McConnon, A., Hollywood, L. E., Cuskelly, G. J., Barnett, J., Raats, M., \& Dean, M. (2014). Let's talk about health: shoppers' discourse regarding health while food shopping. Public Health Nutrition, 18(6), 1001-1010. https://doi.org/10.1017/S1368980014001116. 
O’Connor, E., Cowan, C., Williams, G., O’Connell, J., \& Boland, M. P. (2006). Irish consumer acceptance of a hypothetical second-generation GM yogurt product. Food Quality and Preference, 17(5), 400-411. https://doi.org/10.1016/j.foodqual.2005.05.003.

Onwezen, M. C., Reinders, M. J., van der Lans, I. A., Sijtsema, S. J., Jasiulewicz, A., Dolors Guardia, M., \& Guerrero, L. (2012). A cross-national consumer segmentation based on food benefits: The link with consumption situations and food perceptions. Food Quality and Preference, 24(2), 276-286. https://doi.org/10.1016/j.foodqual.2011.11.002.

Pettigrew, S. (2016). Pleasure: an under-utilised 'P'in social marketing for healthy eating. Appetite, 104, 60-69. https://doi.org/10.1016/j.appet.2015.10.004.

Pettigrew, S., Jongenelis, M. I., Biagioni, N., Pratt, I. S., \& Moore, S. (2018). Results of a long-term follow-up evaluation of an Australian adult nutrition education program. Asia Pacific Journal of Clinical Nutrition, 27(5), 1155. https://doi.org/10.6133/apjen.052018.02.

Pettigrew, S., Moore, S., Pratt, I. S., \& Jongenelis, M. (2016). Evaluation outcomes of a longrunning adult nutrition education programme. Public Health Nutrition, 19(4), 743752. https://doi.org/10.1017/S1368980015001536.

Pettigrew, S., \& Pescud, M. (2013). The salience of food labeling among low-income families with overweight children. Journal of Nutrition Education and Behavior, 45(4), 332-339. https://doi.org/10.1016/j.jneb.2013.01.025.

Poortvliet, P. C., Bérubé-Parent, S., Drapeau, V., Lamarche, B., Blundell, J. E., \& Tremblay, A. (2007). Effects of a healthy meal course on spontaneous energy intake, satiety and palatability. British Journal of Nutrition, 97(3), 584-590. https://doi.org/10.1017/S000711450738135X. 
594

Popkin, B. M. (2017). Relationship between shifts in food system dynamics and acceleration of the global nutrition transition. Nutrition Reviews, 75(2), 73-82. https://doi.org/10.1093/nutrit/nuw064.

Prescott, J., Young, O., O'Neill, L., Yau, N. J. N., \& Stevens, R. (2002). Motives for food choice: A comparison of consumers from Japan, Taiwan, Malaysia and New Zealand. Food Quality and Preference, 13(7), 489-495. https://doi.org/10.1016/S09503293(02)00010-1.

Raghunathan, R., Naylor, R. W., \& Hoyer, W. D. (2006). The unhealthy = tasty intuition and its effects on taste inferences, enjoyment, and choice of food products. Journal of Marketing, 70(4), 170-184. https://doi.org/10.1509/jmkg.70.4.170.

Raulio, S., Ovaskainen, M., Männistö, S., Tapanainen, H., Virtanen, S., \& Peltonen, M. (2015). Adherence to dietary guidelines in FINDIET 2012. European Journal of Public Health, 25(Suppl_3).

Realini, C. E., Kallas, Z., Pérez-Juan, M., Gómez, I., Olleta, J. L., Beriain, M. J., . . Sañudo, C. (2014). Relative importance of cues underlying Spanish consumers' beef choice and segmentation, and consumer liking of beef enriched with n-3 and CLA fatty acids. Food Quality and Preference, 33, 74-85. https://doi.org/10.1016/j.foodqual.2013.11.007.

Rodríguez-Rodríguez, E., Aparicio, A., Aranceta-Bartrina, J., Gil, Á., González-Gross, M., Serra-Majem, L., . . Ortega, R. M. (2017). Low adherence to dietary guidelines in Spain, especially in the overweight/obese population: The ANIBES study. Journal of the American College of Nutrition, 36(4), 240-247. https://doi.org/10.1080/07315724.2016.1248246. 
Salbe, A. D., DelParigi, A., Pratley, R. E., Drewnowski, A., \& Tataranni, P. A. (2004). Taste preferences and body weight changes in an obesity-prone population. The American Journal of Clinical Nutrition, 79(3), 372-378. https://doi.org/10.1093/ajcn/79.3.372

Sautron, V., Péneau, S., Camilleri, G. M., Muller, L., Ruffieux, B., Hercberg, S., et al. (2015). Validity of a questionnaire measuring motives for choosing foods including sustainable concerns. Appetite, 87, 90-97.

Shatenstein, B. (2008). Impact of health conditions on food intakes among older adults. Journal of Nutrition for the Elderly, 27(3-4), 333-361. https://doi.org/10.1080/01639360802265889.

Sobal, J., \& Bisogni, C. A. (2009). Constructing food choice decisions. Annals of Behavioral Medicine, 38(suppl_1), s37-s46.

StataCorp. (2017). Stata Statistical Software: Release 15.1: College Station, TX: StataCorp LLC.

Steenhuis, I. H. M., Waterlander, W. E., \& de Mul, A. (2011). Consumer food choices: The role of price and pricing strategies. Public Health Nutrition, 14(12), 2220-2226. https://doi.org/10.1017/S1368980011001637.

Steptoe, A., Pollard, T. M., \& Wardle, J. (1995). Development of a measure of the motives underlying the selection of food: the food choice questionnaire. Appetite, 25(3), 267284.

Sumithran, P., Prendergast, L., Delbridge, E., Purcell, K., Shulkes, A., Kriketos, A., \& Proietto, J. (2011). Long-term persistence of hormonal adaptations to weight loss. The New England Journal of Medicine, 365(17), 1597-1604. https://doi.org/10.1056/NEJMoa1105816. 
Swait, J. (1994). A structural equation model of latent segmentation and product choice for cross-sectional revealed preference choice data. Journal of Retailing and Consumer Services, 1(2), 77-89. https://doi.org/10.1016/0969-6989(94)90002-7.

Vandevijvere, S., Chow, C. C., Hall, K. D., Umali, E., \& Swinburn, B. A. (2015). Increased food energy supply as a major driver of the obesity epidemic: A global analysis. Bulletin of the World Health Organization, 93(7), 446. https://doi.org/10.2471/BLT.14.150565.

Verain, M. C. D., Sijtsema, S. J., \& Antonides, G. (2016). Consumer segmentation based on food-category attribute importance: The relation with healthiness and sustainability perceptions. Food Quality and Preference, 48, 99-106. https://doi.org/10.1016/j.foodqual.2015.08.012.

Vukmirovic, M. (2015). The effects of food advertising on food-related behaviours and perceptions in adults: A review. Food Research International, 75, 13-19. https://doi.org/10.1016/j.foodres.2015.05.011.

Wardle, J., Haase, A. M., Steptoe, A., Nillapun, M., Jonwutiwes, K., \& Bellisie, F. (2004). Gender differences in food choice: The contribution of health beliefs and dieting. Annals of Behavioral Medicine, 27(2), 107-116. https://doi.org/10.1207/s15324796abm2702_5.

World Health Organisation. (2004). Global Database on Body Mass Index. http://apps.who.int/bmi/index.jsp/ Accessed 8 May 2018.

World Health Organization. (2015). World report on ageing and health (9241565047). Retrieved from https://www.who.int/ageing/events/world-report-2015-launch/en/ Accessed 4 June 2019.

World Health Organization. (2017). Obesity and overweight. http://www.who.int/en/newsroom/fact-sheets/detail/obesity-and-overweight/ Accessed 7 February 2019. 
665

666

667

668

8

10669

11

12670

13

14

15

16

$17 \quad 672$

18

19

20

21

$22 \quad 674$

23

24

25

26

27

28

29

30

31

32

33

34

35

36

37

38

39681

40

41682

42

43

44683

45

$46 \quad 684$

47

48

49685

50

51

52

53

54

55

56

57

58

59

60

61

62

63

64

65 change food behaviour? Asia Pacific Journal of Clinical Nutrition, 11(s3), S579S585. doi:10.1046/j.1440-6047.11.supp3.7.x. 
686 Table 1

687 Sample profile $(\mathrm{n}=1,558)$

\begin{tabular}{ccc}
\hline & $\begin{array}{c}\text { Sample } \\
\%\end{array}$ & $\begin{array}{c}\text { Australian adult } \\
\text { population }\end{array}$ \\
& & $\%$ \\
\hline Gender & 50 & 51 \\
Females & 50 & 49 \\
Males & & \\
Age (in years) & 33 & 33 \\
18-35 & 33 & 34 \\
$36-55$ & 34 & 33 \\
$56+$ & & 40 \\
Socioeconomic status & 49 & 40 \\
Low & 32 & 20 \\
Medium & 19 &
\end{tabular}

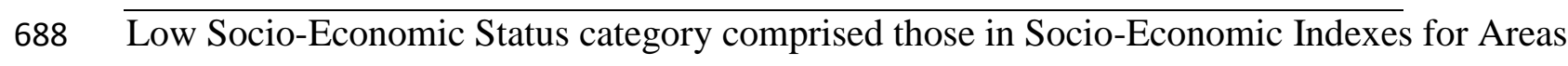
689 (SEIFA) deciles 1 to 4 (ABS, 2018)

690 A ABS, 2017, 2018 
Table 2

693 Mean scores of the food choice factors in the 4-segment latent profile model

\begin{tabular}{|c|c|c|c|c|c|c|c|c|c|}
\hline & \multirow{2}{*}{$\begin{array}{c}\text { Full sample } \\
\mathrm{n}=1,558\end{array}$} & \multicolumn{2}{|c|}{$\begin{array}{c}\text { Segment } 1 \\
\text { High involvement } \\
\mathrm{n}=664 \\
\text { (43\% of sample) }\end{array}$} & \multicolumn{2}{|c|}{$\begin{array}{c}\text { Segment } 2 \\
\text { Moderate involvement } \\
\mathrm{n}=631 \\
(40 \% \text { of sample })\end{array}$} & \multicolumn{2}{|c|}{$\begin{array}{c}\text { Segment } 3 \\
\text { Taste focused } \\
\mathrm{n}=151 \\
\text { (10\% of sample) }\end{array}$} & \multicolumn{2}{|c|}{$\begin{array}{c}\text { Segment } 4 \\
\text { Indifferent } \\
\mathrm{n}=112 \\
\text { (7\% of sample) }\end{array}$} \\
\hline & & Mean (SD) & $\mathrm{Z}$ & Mean (SD) & $\mathrm{Z}$ & Mean (SD) & $\mathrm{Z}$ & Mean (SD) & $\mathrm{Z}$ \\
\hline Taste & $4.42(0.72)^{1}$ & $5.00(0.00)$ & $1.13^{1 \mathrm{a}}$ & $4.00(0.00)$ & $-0.09^{2 b}$ & $5.00(0.00)$ & $1.13^{1 \mathrm{a}}$ & $2.63(0.76)$ & $-1.74^{2 \mathrm{c}}$ \\
\hline Price & $4.19(0.78)^{2}$ & $4.60(0.50)$ & $0.65^{2 \mathrm{a}}$ & $4.13(0.62)$ & $0.07^{1 b}$ & $3.46(0.78)$ & $-0.75^{2 \mathrm{c}}$ & $3.12(1.08)$ & $-1.16^{1 \mathrm{~d}}$ \\
\hline Healthiness & $4.07(0.82)^{3}$ & $4.39(0.70)$ & $0.39^{3 \mathrm{a}}$ & $3.98(0.64)$ & $-0.11^{2 b}$ & $3.87(0.93)$ & $-0.24^{2 b}$ & $2.93(1.04)$ & $-1.39^{1 \mathrm{c}}$ \\
\hline Convenience & $3.79(0.82)^{4}$ & $4.19(0.67)$ & $0.14^{4 a}$ & $3.69(0.66)$ & $-0.46^{3 \mathrm{~b}}$ & $3.07(0.81)$ & $-1.22^{4 c}$ & $2.88(0.93)$ & $-1.44^{1 \mathrm{c}}$ \\
\hline
\end{tabular}

694 Note: Different letters within a row indicate significant differences between segments and different numbers within a column indicate significant 695 differences within segments on the z-scores of the food choice factors of taste, price, healthiness, and convenience. Mean scores are out of a maximum of 5 . 


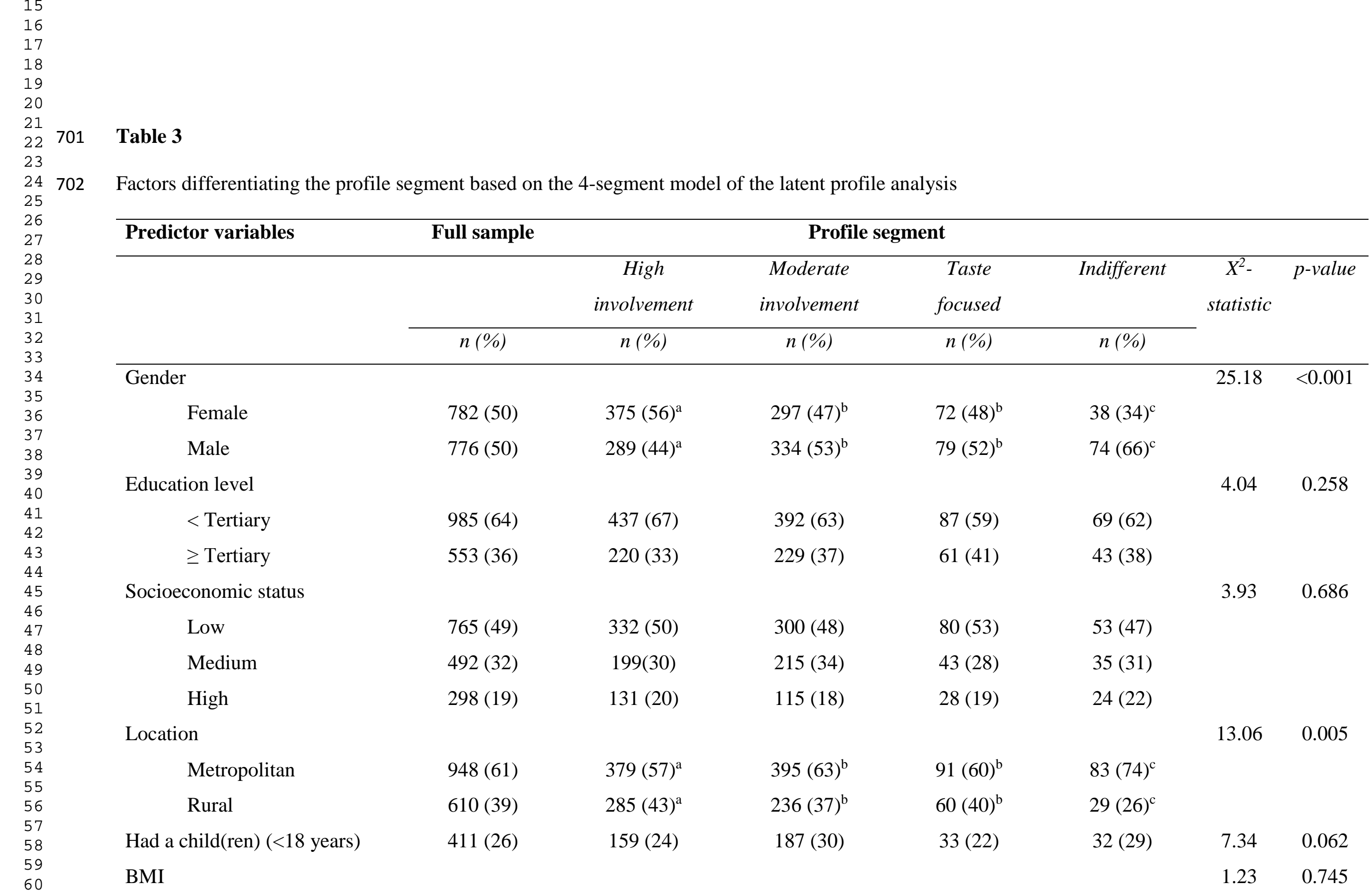




\section{Author statement}

Conceptualization: SP, LD

Data curation: LD

Formal analysis: LD

Funding acquisition: SP, HD, CM, BN, BK, KB

Methodology: LD, SP, HD, CM, BN, BK, KB

Writing - original draft: LD, KC, SP

Writing - review \& editing: All authors 